\title{
A RESEARCH ON THE SOCIAL RESPONSIBILITY EFFICIENCY OF CHINESE LISTED FOOD COMPANIES
}

\author{
- Research paper - \\ Weimei ZHANG \\ Hunan City University, Yiyang, China \\ Central South University of Forestry and Technology, Changsha, China
}

\begin{abstract}
On the basis of establishing an input-output index system of listed food companies' social responsibility, this paper uses the DEA model to assess 22 Chinese listed food companies' social responsibility efficiency between 2014 and 2016. Results show that the social responsibility efficiency of Chinese listed food companies is generally lower and the average of the 22 companies is only 0.665 . The social responsibility management in $81.80 \%$ of listed food companies is in a relatively ineffective state. There is a big room for improvement. In addition, the social responsibility efficiencies of listed companies with different sizes are quite different. The social responsibility efficiency of large-sized listed food company is obviously higher than that of the small and medium-sized. The study also shows that the social responsibility efficiencies of most listed food companies are in the stage of increasing returns to scale and more input would be necessary in order to achieve higher efficiency.
\end{abstract}

Keywords: Data envelopment analysis; Chinese food companies; Social responsibility; Efficiency

\section{INTRODUCTION}

In a modern complex society, there is not any company with one single identity. Companies, as independently-operating and self-financing economic organizations, are committed to pursuing the maximization of profits. Meanwhile, companies are obliged to fulfill social responsibilities and meet social needs in accordance with the fiduciary responsibility from investors, the state, and society. Because of the close connection between public health and food safety, the high degree of social concern, the strong dependent impacts between food companies, and many other factors, the social responsibility of food companies is particularly critical. China is a big country for food production and consumption. Most food companies actively fulfill their social responsibilities. They stick to the lawful production and management, and honesty and business credit, protecting consumers' rights and interest, which help them to establish good public images. However, there are still some food companies, which produce and sale food with potential safety problems in order to pursue profits, regardless of social responsibilities. For example, the exposure of the notorious "poison milk powder" incident of Sanlu Group and the "Clenbuterol" incident of Shuanghui Group not only damaged the interests of consumers, but also caused serious social effects.

Corporate Social Responsibility (CSR) was initially proposed by the British scholar Sheldon in 1924. Dodd (1932) believed that companies should also serve the society and take social responsibility when they are dedicated to generating profits. Bowen (1954) argued that companies should voluntarily

${ }^{1}$ Corresponding author. Mailing address: zhweimei@126.com 
care about social interests and carry out business activities. In 1965, Professor Rudder of Northwestern University of the United States suggested that relying on the traditional theory of profit maximization could not deny that corporate responsibility should be assumed. Within the framework of business principles, there are many opportunities of applying corporate capitals to valuable public welfare, but the only limitation is whether the company's policies have a reasonable relationship with the long-term interests of the company. At this point the supporters of corporate social responsibility have prevailed and most scholars acknowledged that corporate social responsibility is necessary. A well-known scholar, Archie B. Carroll, presented the pyramid idea of corporate social responsibility in 1979, which defined that the complete social responsibility should include: economic responsibility, that is, companies must be profitable to survive; legal responsibility, that is, companies must operate by the law; moral responsibility, that is, employees must be obliged to work fairly and impartially; charitable responsibility, which makes companies qualified corporate citizens. Although currently the academic community has not developed a universally accepted concept of corporate social responsibility, a consensus does exist, that is, companies should consider the interests of employees, consumers, society, and other relevant stakeholders and take social responsibilities in the creation of profits. Afterwards, scholars, including Peters \& al. (2011), André (2012), Lopez \& Fornes (2015), Patten \& al. (2015), have established different corporate social responsibility frameworks.

As for how to evaluate the commitment of corporate social responsibility, scholars mainly focused on three aspects, that is, dealing with social issues, stakeholder requirements, and financial performance. At the very beginning, scholars tried to evaluate the corporate social responsibility by means of assessing companies' involvement in social issues. Folger and Nurt evaluated the corporate social responsibility from the perspective of the impacts of corporate behaviors on social issues. They used the pollution index as the technical indicator. Preston, a member of Canadian Corporate Royal Committee, focused on the empirical study of corporate social responsibility. $\mathrm{He}$ pointed out four stages according to the degree of companies' involvement in dealing with social issues, that is, recognizing-the-issue stage, analyzing-and-planning stage, policy-making stage, and implementation stage. $\mathrm{He}$ evaluated the corporate social responsibility through the degree of companies' involvement in social issues. Clement (1979) also conducted in-depth researches on the evaluation of corporate social responsibility and he believed that the social issues in front of companies are mainly from three aspects, that is, environment protection, sales service, and employment discrimination, which should be used to evaluate the corporate social responsibility. So he established a three-dimensional evaluation model. Another breakthrough in the field of corporate social responsibility research is to use financial indicators to evaluate the performance of corporate social responsibility. Cochran and Wood adopted new techniques to study the relationship of corporate social responsibilities and financial performance in different industries and results showed that there is a clear positive correlation between corporate social responsibilities and corporate financial performances in one same industry. In the $1990 \mathrm{~s}$, after the proposal of Balanced Scorecard Indicator, Kaplan and Norton integrated the stakeholders' requirements and established an evaluation system regarding finance, customers, internal procedures, and learning and growing as the fundamental dimensions. This framework can comprehensively evaluate the relationship between corporate social responsibility and financial performance.

Corporate social responsibility efficiency, that is, the effectiveness of corporate social responsibility input, is a concept of economic input and output. At present the corporate social responsibility efficiency is 
usually measured by nonparametric analysis method. The data envelopment analysis (DEA) is a representative of nonparametric analysis method, which can be used to estimate the efficiency of multi-input and multi-output innovation. DEA method does not need to set the specific function of production frontier, which avoids the improper function setting error. On the basis of previous research results, following the principles of data availability, testability,

\section{MATERIALS AND METHODS}

The methodology of this study is Data Envelopment Method (DEA). The method of DEA was first proposed in 1978 by Charnes, a well-known US operations scientist, and Cooper, based on the concept of "relative efficiency evaluation". It uses a linear programming model to evaluate the relative efficiency of decision-making units with multi inputs and multi outputs and is one of the most commonly used nonparametric frontier efficiency analysis methods.

Assume that there are $\mathrm{n}$ decision-making units $\left(\mathrm{DMU}_{\mathrm{j}}, \quad \mathrm{j}=1 \ldots \mathrm{N}\right)$ and each

$$
\left.\begin{array}{ll}
\max & h_{0}=\frac{u^{T} Y_{0}}{v^{T} X_{0}} \\
\text { s.t. } & \frac{u^{T} Y_{\mathrm{j}}}{v^{T} X_{\mathrm{j}}} \leq 1 j=1,2, \cdots, \mathrm{N}
\end{array}\right\} \begin{aligned}
& \\
& v=\left(v_{1}, v_{2}, \cdots, v_{m}\right)^{T} \geq 0 \\
& u=\left(u_{1}, u_{2}, \cdots, u_{s}\right)^{T} \geq 0
\end{aligned}
$$

decision-making unit has a total of $\mathrm{m}$ kinds of inputs and s kinds of outputs, where the input of the decision-making unit $\mathrm{DMU}_{\mathrm{j}}$ is expressed as $X_{j}=\left(x_{1 j}, x_{2 j}, \ldots, x_{m j}\right)^{T}$ and the output is $Y_{j}=\left(y_{1 j}, y_{2 j}, \ldots, y_{s j}\right)^{T}$. Here, $v$ is the weight vector of the input vector $X, u$ the weight vector of the output vector $\mathrm{Y}$, and $\mathrm{h}_{\mathrm{j}}$ the efficiency evaluation index of the $j^{\text {th }}$ decision-making unit $\mathrm{DMU}_{\mathrm{j}}$. To evaluate the efficiency of $\mathrm{DMU}_{0}$, the original DEA model is as follow:

To facilitate the calculation, we introduce the relaxation variables $\mathrm{s}^{-}$and $\mathrm{s}^{+}$. Then the formula (1) can be converted into the following multiple linear programming model presented in Eq. 2.

$$
\left.\begin{array}{l}
\min \theta \\
\text { s.t. } \quad \sum_{j=1}^{N} \lambda_{j} x_{j}+\mathrm{s}^{-}=\theta x_{0} \\
\sum_{j=1}^{N} \lambda_{j} y_{j}-\mathrm{s}^{+}=y_{0} \\
\lambda_{j} \geq 0, j=1,2, \cdots, \mathrm{N} \\
\mathrm{s}^{+} \geq 0, \mathrm{~s}^{-} \geq 0
\end{array}\right\}
$$

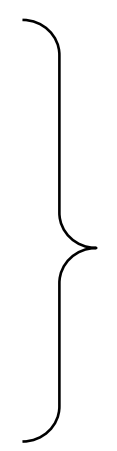

Get the solution of formula (2) and make $\theta^{*}, S^{-*}, S^{+* *}$ the optimal solutions. The results are as follows:
If $\theta^{*}=1$ and the relaxation variables are all zero, it indicates that the decision-making unit is valid for DEA and activities of the 
decision-making unit are effective in terms of technology and scale.

If $\theta^{*}=1$ and the relaxation variables are not all zero, it indicates that the decision-making unit is poorly valid for DEA and activities of the decision-making unit are not always effective in terms of both technology efficiency and scale.

If $\theta^{*} \prec 1, \quad$ it indicates that the decision-making unit is invalid for DEA and economic activities are neither best for the technology efficiency or for the scale.

\section{THE INDICATORS AND THE DATA SOURCE}

\section{The selection of indicators}

When applying the DEA method, it is necessary to establish the input and output indicator system. In terms of social responsibility efficiency of food companies, the fundamental idea is that food companies should pursue for the maximization of output as well as the minimization of inputs in the process of fulfilling social responsibilities, which is in accordance with the requirements for input and output indicators of DEA method. On the basis of domestic and foreign researches on the selection of input and output indicators for the evaluation of corporate social responsibility, considering data availability, we establish an indicator system, shown in Table1, to evaluate the corporate social responsibility efficiency of food companies.

\section{(1) Input indicators}

Consumer input: expressed as "business cost ratio". Business cost is an important cost of food companies in operations, which represents the value of food companies inputting in food products. The higher the proportion of business cost to business return is, the more the consumer responsibility of a food company would be.

Shareholder input: expressed as "return ratio of equity". Return of equity represents the value created by listed food companies for shareholders. Regardless of whether the company distributes dividends, the return of
If $\sum \lambda_{j}^{*}=1$, it means the scale returns of decision-making unit does not change. If $\sum \lambda_{j} \prec 1$, it means increased scale returns of the decision-making unit, indicating that increasing inputs caring more outputs proportionally. If $\sum \lambda_{j} \succ 1$, it means decreased scale returns of the decision-making unit, indicating that more inputs cannot bring more outputs accordingly.

equity can be reflected by the increase of corporate value. A higher return ratio of equity indicates that the listed food companies well fulfill the responsibility to its shareholders.

Table1. The indicator system to evaluate the corporate social responsibility efficiency of food companies.

\begin{tabular}{|c|c|c|}
\hline $\begin{array}{l}\text { First- } \\
\text { grade } \\
\text { indicator }\end{array}$ & $\begin{array}{l}\text { Second- } \\
\text { grade } \\
\text { indicator }\end{array}$ & $\begin{array}{l}\text { Third-grade } \\
\text { indicator }\end{array}$ \\
\hline \multirow{5}{*}{ Input } & $\begin{array}{l}\text { Consumer } \\
\text { input }\end{array}$ & $\begin{array}{l}\text { Business cost ratio } \\
\left(\mathrm{x}_{1}\right)\end{array}$ \\
\hline & $\begin{array}{l}\text { Shareholde } \\
r \text { input }\end{array}$ & $\begin{array}{l}\text { Return ratio of } \\
\text { equity }\left(\mathrm{x}_{2}\right)\end{array}$ \\
\hline & $\begin{array}{l}\text { Creditor } \\
\text { input }\end{array}$ & Equity ratio $\left(\mathrm{x}_{3}\right)$ \\
\hline & $\begin{array}{l}\text { Employee } \\
\text { input }\end{array}$ & $\begin{array}{l}\text { Employee } \\
\text { profitability }\left(\mathrm{x}_{4}\right)\end{array}$ \\
\hline & Social input & $\begin{array}{l}\text { Social contribution } \\
\text { ratio }\left(\mathrm{x}_{5}\right)\end{array}$ \\
\hline \multirow[t]{2}{*}{ output } & $\begin{array}{l}\text { Investment } \\
\text { rating } \\
\text { output }\end{array}$ & $\begin{array}{l}\text { Average } \\
\text { investment rating } \\
\text { of research report } \\
\left(\mathrm{y}_{1}\right)\end{array}$ \\
\hline & $\begin{array}{l}\text { Economic } \\
\text { output }\end{array}$ & $\begin{array}{l}\text { Return on assets } \\
\left(\mathrm{y}_{2}\right)\end{array}$ \\
\hline
\end{tabular}

Creditor input: expressed as "equity ratio". Equity capital is the basis for listed food companies paying debts. A higher proportion of equity capital to total asset means the 
company provides better guarantees for overall debts and bears more responsibility for its creditors.

Employee input: expressed as "employee profitability". It reflects the cost of a company to attract, employ, and keep its employees. The higher the employee profitability, the greater the responsibility of the food company inputs in employee interests.

Social input: expressed as "social contribution ratio". Social donations and taxes represent the contribution of food companies to the society. The higher proportion of social contributions to revenues indicates that food companies fulfill their external responsibilities better.

\section{(2) Output indicators}

Investment rating output: expressed as "the average investment rating in research report". The investment rating of listed food companies represents the market's outlook for investment value. A higher investment rating would be good for attracting more investors. The investment rating given by the research report generally includes five levels from negative to positive, with a scale of 1 to 5. Usually, for a certain period of time, a listed food company can receive multiple investment ratings. We use the average to represent the investment rating during the specific period. The higher the average is,

\section{RESULTS AND DISCUSSIONS}

\section{Analysis of the frontier of social responsibility efficiency of listed food companies}

As can be seen from Table 2, the social responsibility efficiency of listed food companies is generally not high. The average of overall efficiency is only 0.665 . There are $33.5 \%$ of the room for improvement. Of the 22 listed companies, only four companies (accounting for 18.2\%) have an overall social responsibility efficiency of 1 , which is at the frontier of efficiency. It means that the four companies have appropriate proportions of social responsibility input and output and the better the food company can attract investors.

Economic output: expressed as "return on assets (ROA)". The return on assets can measure the profit per unit of assets, which can be used to evaluate the corporate performance. Here we use it as the second output indicator and the calculation method is: $\mathrm{ROA}=($ total profit + interest expense $) /$ total assets.

\section{Data sources}

Taking into account the availability and representativeness of data, in this paper we choose 22 food companies listed in the mainland market of China as the objects of empirical research. Meanwhile, considering the time circle of companies fulfilling social responsibility and the time lag between input and output, in this paper we firstly calculate the annual average of social responsibility input and output of each listed company from 2014 to 2016, and then estimate the social responsibility efficiency of each company. The original data used in the calculation are mainly derived from the annual reports of listed companies from 2014 to 2016.

The software deap2.1 was used to perform the DEA. Input relevant data of the 22 listed food companies into the software and get the overall efficiency, pure technology efficiency, and the scale efficiency of each company from 2014 to 2016.

they are in a DEA-valid status. In other words, with current input, the output has reached the best scale, without waste of input or lack of output.

There are 18 companies (accounting for $81.8 \%$ ) with overall social responsibility efficiency less than 1 , indicating relative ineffectiveness of these companies' social responsibility input and output efficiency. For these non-frontier companies, there are still room for further improvement of social responsibility input and output efficiency. They should adjust the allocation and proportion of resources, improve the 
organization and management, and make

responsibility activities, so that the social them properly work with social responsibility efficiency might be enhanced.

Table 2. The evaluation results of social responsibility efficiency of listed food companies 2014-2016.

\begin{tabular}{|l|l|l|l|l|}
\hline No. & Overall efficiency & Pure technology efficiency & Scale efficiency & Return to scale \\
\hline $\mathrm{D}_{1}$ & 1 & 1 & 1.000 & Unchanged \\
\hline $\mathrm{D}_{2}$ & 1 & 1 & 1.000 & Unchanged \\
\hline $\mathrm{D}_{3}$ & 1 & 1 & 1.000 & Unchanged \\
\hline $\mathrm{D}_{4}$ & 1 & 1 & 1.000 & Unchanged \\
\hline $\mathrm{D}_{5}$ & 0.983 & 1 & 0.983 & Increasing \\
\hline $\mathrm{D}_{6}$ & 0.98 & 1 & 0.980 & Increasing \\
\hline $\mathrm{D}_{7}$ & 0.964 & 1 & 0.964 & Increasing \\
\hline $\mathrm{D}_{8}$ & 0.901 & 1 & 0.901 & Increasing \\
\hline $\mathrm{D}_{9}$ & 0.872 & 1 & 0.872 & Increasing \\
\hline $\mathrm{D}_{10}$ & 0.702 & 1 & 0.702 & Increasing \\
\hline $\mathrm{D}_{11}$ & 0.653 & 1 & 0.653 & Increasing \\
\hline $\mathrm{D}_{12}$ & 0.556 & 1 & 0.556 & Increasing \\
\hline $\mathrm{D}_{13}$ & 0.544 & 0.951 & 0.572 & Increasing \\
\hline $\mathrm{D}_{14}$ & 0.525 & 0.912 & 0.576 & Decreasing \\
\hline $\mathrm{D}_{15}$ & 0.426 & 0.903 & 0.472 & Decreasing \\
\hline $\mathrm{D}_{16}$ & 0.419 & 0.939 & 0.446 & Increasing \\
\hline $\mathrm{D}_{17}$ & 0.417 & 0.821 & 0.508 & Increasing \\
\hline $\mathrm{D}_{18}$ & 0.396 & 0.906 & 0.437 & Increasing \\
\hline $\mathrm{D}_{19}$ & 0.363 & 0.781 & 0.465 & Increasing \\
\hline $\mathrm{D}_{20}$ & 0.351 & 0.873 & 0.402 & Decreasing \\
\hline $\mathrm{D}_{21}$ & 0.292 & 0.754 & 0.387 & Increasing \\
\hline $\mathrm{D}_{22}$ & 0.281 & 0.556 & 0.505 & Increasing \\
\hline Average & 0.665 & 0.927 & 0.717 & \\
\hline & & & & \\
\hline
\end{tabular}

Analysis of the difference of social responsibility efficiency of listed food companies of different sizes

In terms of the size of company, the 22 samples include 10 large-sized and 12 small and medium-sized companies in this research (table 3). Generally, large food companies have relatively higher social responsibility efficiency, with an average overall efficiency of 0.902 , while small and medium-sized companies have lower social responsibility efficiency, with an average efficiency of 0.468 . And among the four frontier food companies in terms of social responsibility efficiency, three of them are large companies, and only one small and medium-sized company. It indicates that the social responsibility efficiency of small and medium-sized company is relatively low, and it is necessary to improve the social responsibility efficiency by increasing social responsibility input and improving the management level.

Table 3. Analysis of the difference of social responsibility efficiency of food companies of different sizes

\begin{tabular}{|l|l|l|l|}
\hline \multicolumn{1}{|c|}{ Size } & Total & Average overall efficiency & $\begin{array}{l}\text { Total number of DEA valid } \\
\text { companies }\end{array}$ \\
\hline Large & 10 & 0.902 & 3 \\
\hline Small and medium & 12 & 0.468 & 1 \\
\hline Total & 22 & 0.665 & 4 \\
\hline
\end{tabular}


Analysis of the difference of pure technology efficiency and scale efficiency of listed food companies

As shown in Table 2 and Table 4., the average of pure technology efficiency of all sample companies is 0.927 . And 12 companies are effective in terms of pure technology efficiency, accounting for $54.54 \%$ of the total sample size. The average of scale efficiency of all sample companies is 0.717 . And 4 companies are effective in terms of scale efficiency, accounting for
$18.18 \%$ of the total sample size. In this research, the scale efficiency is significantly lower than the pure technology efficiency on average. The scale efficiency is relatively low, indicating that the key factor restricting the social responsibility efficiency of listed companies is the scale efficiency. Therefore, listed food companies should increase the input of social responsibility to achieve the economies of scale, thereby enhancing the social responsibility efficiency.

Table 4. The pure technology efficiency and scale efficiency of food companies.

\begin{tabular}{|l|l|l|l|l|l|}
\hline $\begin{array}{l}\text { Pure technology } \\
\text { efficiency }\end{array}$ & Total & Percentage & $\begin{array}{l}\text { Scale } \\
\text { efficiency }\end{array}$ & Total & Percentage \\
\hline 1 & 12 & $54.54 \%$ & 1 & 4 & $18.18 \%$ \\
\hline$[0.9,1]$ & 5 & $22.73 \%$ & {$[0.9,1]$} & 4 & $18.18 \%$ \\
\hline$(-\infty, 0.9)$ & 5 & $22.73 \%$ & $(-\infty, 0.9)$ & 14 & $63.64 \%$ \\
\hline Total & 22 & $100 \%$ & Total & 22 & $100 \%$ \\
\hline
\end{tabular}

\section{Analysis of the return to scale of social responsibility efficiency of listed food companies}

The term of return to scale explains the changes in output relative to the associate changes in the inputs (the factors of production) within companies in the context of unchanged other conditions. The increase of return to scale is the case where the output of the company increases at a rate higher than the input increases. The decrease of return to scale is the case where the output of the company increases at a rate lower than the input increases. It can be seen from Table 5. that, in terms of social responsibility, there are four companies with unchanged return to scale, accounting for $18.18 \%$ of the total sample, and fifteen companies with increased return to scale, accounting for $68.18 \%$, and three companies with decreased return to scale, and accounting for $13.64 \%$.

\section{CONCLUSIONS}

In view of the above empirical analysis of the social responsibility efficiency of listed food companies in 2014-2016 and the discussion of analysis results, s conclusions can be drawn.
Table5. The return to scale of listed food companies in terms of social responsibility efficiency

\begin{tabular}{|l|l|l|}
\hline Return to scale & Total & Percentage \\
\hline Unchanged & 4 & $18.18 \%$ \\
\hline Increased & 15 & $68.18 \%$ \\
\hline Decreased & 3 & $13.64 \%$ \\
\hline Total & 22 & $100 \%$ \\
\hline
\end{tabular}

Apparently, for most of listed companies in this research, the social responsibility efficiency is at the stage of increased return to scale, which indicates that these companies have not achieved the optimal scale of social responsibility. With the increase of social responsibility input, the output increases at a rate higher than the input increases, which reflects the inadequate investment of these companies in the process of fulfilling social responsibility.

First of all, the social responsibility efficiency of most listed food companies is far from the effective state, and there is a big room for improvement. Food companies should further increase their social responsibility input, adjust the allocation structure of resources, establish advanced 
corporate social responsibility management mechanism, and vigorously improve the effectiveness of corporate social responsibility, enhancing the corporate image in society and promoting the sustainable development of company.

Secondly, there is a significant difference in the social responsibility efficiency of listed companies with different sizes. Large food companies are clearly ahead of small and medium-sized companies in terms of social responsibility efficiency. Therefore, large companies should continue to maintain their advantages and stabilize the corporate social responsibility efficiency. Small and medium-sized food companies should take advantage of follow-up development and improve the corporate social responsibility efficiency by imitating and learning from large food companies advanced management experiences, which may finally result in catching up the large food companies.

Thirdly, for the vast majority of listed food companies, the pure technology efficiency is greater than the scale efficiency, and for most food companies, the return to scale is increasing, which indicates that social responsibility input is the main factor influencing the social responsibility efficiency of listed food companies. At present the social responsibility input of Chinese listed food companies is insufficient, most companies should increase the investment in social responsibility.

\section{ACKNOWLEDGEMENTS}

The social science association project in Hunan province (XSPYBZZ007).

\section{REFERENCES}

1. André, R. (2012). Assessing the accountability of the benefit corporation: will this new gray sector organization enhance corporate social responsibility? Journal of Business Ethics, 110(1), 133-150. DOI: 10.1007/s10551-012-1254-1.

2. Bowen, H. R., Gond, J. P., \& Bowen, P. G. (1954). Social responsibilities of the businessman. American Catholic Sociological Review, 15(1), 42. DOI: 10.2307/3708003.

3. Carroll, A. B. (1979). A three-dimensional conceptual model of corporate performance. Academy of Management Review, 4(4), 497-505. DOI: 10.2307/257850.

4. Clement, W. (1979). The royal commission on corporate concentration: comment. Canadian Public Policy, 5(1), 120-126. DOI: 10.2307/3550228

5. Cochran, P. L., \& Wood, R. A. (2005). Corporate social responsibility and financial performance. Corporate Governance, 27(3), 129-138. DOI: 10.2307/255956.

6. Dodd, E. M. (1932). For whom are corporate managers trustees?. Harvard Law Review, 45(7), 1145-1163. DOI: $10.2307 / 1331697$.

7. Fogler, H. R., \& Nutt, F. (1975). A note on social responsibility and stock valuation. Academy of Management Journal, 18(1), 155-160. DOI: 10.2307/255635

8. Kaplan, R. S., \& Norton, D. P. (1992). The balanced scorecard - measure that drive performance. Harvard Business Review, (January-February), 71-79. DOI: 00178012.

9. Lopez, B. \& Fornes, G. (2015). Corporate social responsibility in emerging markets: case studies of Spanish MNCs in Latin America. European Business Review. 27(2), 214-230. DOI:10.1108/EBR-03-2013-0053.

10. Peters, S. Miller, M., \& Kusyk, S. (2011). How relevant is corporate governance and corporate social responsibility in emerging markets? Corporate Governance, 11(4), 429-445. DOI:/10.1108/ 14720701111159262.

11. Patten, D. M., Ren, Y. \& Zhao, N. (2015). Standalone corporate social responsibility reporting in China: an exploratory analysis of its relation to legitimation. Social and Environmental Accountability Journal. 35 (1), 17-31. DOI:10.1080/1540496X.2015.1021594.

12. Sheldon, O. (1924). The Philosophy of Management. London: Sir Isaac Pit-man and Sons Ltd. 